\title{
Complications of vasectomy
}

\section{NINAAD S AWSARE, JAI KRISHNAN, GREG B BOUSTEAD, DAMIAN C HANBURY, THOMAS A McNICHOLAS}

\author{
Department of Urology, Lister Hospital, Stevenage, UK
}

ABSTRACT

INTRODUCTION Vasectomy is a common method of sterilisation. However, it is less popular than tubal ligation world-wide. It is also a frequent cause of litigation relating to its complications. This article reviews the early and late risks associated with the procedure.

PATIENTS AND METHODS Data collection was done using the internet to search Medline for obtaining evidence-based medicine reviews. Cross-references were obtained from key articles. Websites of government bodies and medical associations were searched for guidelines relating to vasectomy.

DISCUSSION Early complications include haematoma, wound and genito-urinary infections, and traumatic fistulae. Vasectomy failure occurs in $0-2 \%$ of patients. Late recanalisation causes failure in $0.2 \%$ of vasectomies. Significant chronic orchalgia may occur in up to $15 \%$ of men after vasectomy, and may require epididyectomy or vasectomy reversal. Antisperm antibodies develop in a significant proportion of men post-vasectomy, but do not increase the risk of immune-complex or atherosclerotic heart disease. Similarly, vasectomy does not enhance risk of testicular or prostate cancer. Vasectomy has a lower mortality as compared to tubal occlusion, but is still significantly high in non-industrialised countries because of infections.

CONCLUSIONS Vasectomy, though safe and relatively simple, requires a high level of expertise to minimise complications. Adequate pre-operative counselling is essential to increase patient acceptability of this method of permanent contraception.

\section{KEYWORDS}

Vasectomy - Complications - Bleeding - Infection - Chronic pain - Prostate cancer - Sterilisation death

\section{CORRESPONDENCE TO}

Ninaad S Awsare, Department of Urology, University Hospital of Wales, Heath Park, Cardiff CF14 4XW, UK

M: +44 (0)7799 008021; F: +44 (0)2920 744179; E: ninaad_awsare@hotmail.com

Sterilisation is the principal method of contraception worldwide. ${ }^{1}$ In $2001,15 \%$ of British men aged $16-64$ years had a vasectomy. ${ }^{2}$ The General Practice Research database reveals that there were about 64,422 vasectomies preformed in England in 1999 in the National Health Service and charitable sector. $^{3}$ World-wide, about 190 million couples use tubal ligation (TL), while 42 million men have had a vasectomy. ${ }^{4}$ This suggests that vasectomy is less acceptable than TL, although it is thought to be associated with fewer risks than TL. ${ }^{5}$ It is performed in both the primary care setting by GPs and in secondary care by urologists and surgeons. Guidelines laid down by the Royal College of Obstetricians and Gynaecologists (RCOG, January 2004) ${ }^{5}$ specify the standard of training required. Vasectomy is performed at request, on mainly healthy men as a voluntary method of permanent sterilisation. However, it is also a frequent cause for litigation arising from complications, including claims for failed sterilisation. ${ }^{6,7}$ The purpose of this article is to highlight the common complications, list the rare ones, and review the current understanding of the more controversial risks that were associated with vasectomy in the past.

\section{Patients and Methods}

Data were collected by an internet search. Ovid was used to obtain EBM (evidence-based medicine) reviews. A Medline search was performed using the search terms: 'vasectomy complications', 'vasectomy + infection', 'vasectomy + endocarditis', 'vasectomy + failure', 'vasectomy + cancer', and 'vasectomy + death'. Cross-references were obtained from lead articles. In addition, web-sites of the following organisations were searched for guidance on the procedure of vasectomy: NICE (National Institute for Clinical Excellence), Royal College of Surgeons of England, Royal College of General Practitioners, RCOG, and the American Urological Association (AUA).

\section{Results and Discussion}

The national evidence-based guideline of RCOG $^{5}$ has been devised to help practitioners perform vasectomy safely and effectively, and it specifies the standard of care. It recommends the no-scalpel approach using vas division 


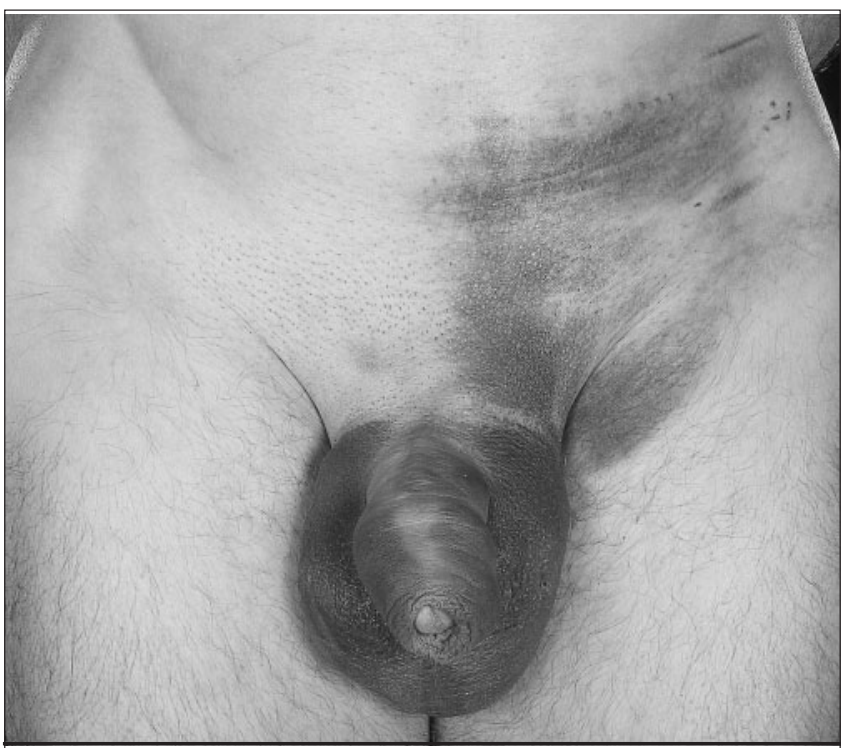

Figure 1 Massive haematoma involving the scrotum, penis and anterior abdominal wall in a patient following vasectomy. Scrotum shows vasectomy incisions.

with fascial interposition or intraluminal diathermy, since this method has lower short-term complications ${ }^{8}$ with higher success rate 9,10 $^{9}$ as compared to the incision technique without the above measures. It also recommends the use of local anaesthesia (LA), it being safer than general anaesthesia (GA), unless contra-indicated or patient preference. ${ }^{5}$ It may be difficult to tackle complications such as bleeding vessels, especially in the primary care setting, without the benefit of backup GA. Leissner et al., ${ }^{11}$ however, reported that the incidence of complications depends on the surgeon's experience and technique, and not whether it is done as an in-patient or out-patient procedure.

Literature review of the early and late complications and consensus on the current understanding of risks associated with vasectomy follows. Rare complications have been included for the purpose of completion.

\section{Early complications}

\section{HAEMATOMA FORMATION}

This is a common complication of vasectomy (see Fig. 1), with an incidence of about $2 \%$ (range, $0.09-29 \%$ ). ${ }^{12}$ The incidence of haematoma formation seems to correlate with the surgical experience. The haematoma rate was $4.6 \%$ for those performing 1-10 vasectomies per year, as against $1.6 \%$ for those performing $11-50$ vasectomies a year. ${ }^{12}$ Goldstein ${ }^{13}$ recommended leaving the vasectomy incision open, as this heals rapidly and prevents haematoma accumulation. The no-scalpel technique minimises dissection, and thus decreases haematoma formation. ${ }^{8}$

\section{INFECTION}

The incidence of infection varies between $12-38 \%$, with an average of about $3.4 \% .{ }^{14,15}$ This includes wound, urinary and epididymal infection. Haematoma formation, ${ }^{14}$ as well as pre-operative positive semen and urine cultures are reported risk factors. ${ }^{15,16}$ Special infections include:

1. Fournier's gangrene - this is a rare, but potentially lethal, complication. Four cases (including one death) have been reported ${ }^{17-19}$ in otherwise fit young men, although one patient had an intercurrent diarrhoeal illness at the time of vasectomy.

2. Syphilis - primary bilateral chancre of the wound developed in one patient following post-vasectomy sexual exposure. ${ }^{20}$

3. Endocarditis - post-vasectomy coagulase-negative staphylococcal endocarditis requiring valvular reconstruction has been reported in 7 previously normal valves. ${ }^{21-24}$ The aortic valve seemed to be most commonly involved, and Staphylococcus lugdenensis was implicated in 5 of the cases.

\section{Trauma}

There are very few reports of injury to neighbouring structures during vasectomy. A small series of 150 patients on whom no-scalpel vasectomy was performed reported a $4.7 \%$ incidence of perforated small or occult hydrocoele with no long-term morbidity. ${ }^{25}$ Genitofemoral neuralgia requiring neurectomy has been reported following nerve injury during vasectomy. ${ }^{26}$

\section{DELAYED PRESENTATION FOLLOWING VASECTOMY}

Some patients present months to years later following their vasectomy, often with cutaneous fistulae.

1. Vasocutaneous and vaso-urinary fistula - ten cases have been reported, with patients presenting several years after surgery. ${ }^{27,28}$ Vasocutaneous fistulae probably result following a sperm granuloma at the site of vasectomy, which adheres to the skin incision. ${ }^{29}$ Vasocutaneous urinary fistula generally occurs in the presence of an underlying voiding dysfunction, such as neurogenic bladder or bladder outflow obstruction, leading to high pressure voiding and reflux of urine into the vas..$^{27,28}$

2. Vasovenous fistula - a patient presented 3 months' postvasectomy with haematuria and haematospermia that was cured by surgical excision. ${ }^{30}$

3. Arteriovenous fistula - a patient presented 10 years' post-vasectomy with a scrotal mass, surgery on which suggested fistula between the deferential artery and a pampiniform plexus vein. ${ }^{31}$

\section{Late effects}

\section{SPERM GRANULOMA}

These develop microscopically at the vasectomy site, epididymis or rete testis in $10-30 \%$ of cases. ${ }^{13}$ Granuloma 
formation may help vent high intra-epididymal pressure and prevent damage. ${ }^{32}$ Granulomas are implicated in spontaneous vas recanalisation and return of fertility. ${ }^{33}$

\section{Failure}

Vasectomy failures can be due to inadequate occlusion of one or both vasa, unprotected intercourse before semen is azoospermic or recanalisation, with a reported frequency of $0-2 \% .^{5}$ Early recanalisation is recognised by an initial azoospermic sample followed rapidly by a rising sperm count, and is the basis for two semen analyses post-vasectomy. ${ }^{5}$ Late recanalisation, first reported by Philp et al. ${ }^{34}$ occurs in about one in 2000 vasectomies. ${ }^{5}$ A comparative, non-randomised study of two methods involving 3761 vasectomies by a single surgeon showed higher failure for clipping and excision of vas segment $(8.7 \%)$ versus clipping, thermal cautery with fascial interposition $(0.3 \%) .{ }^{35}$ Two randomised, controlled trials also showed a higher success rate with the use of fascial interposition. ${ }^{9,10}$

\section{CLEARANCE AFTER VASECTOMY}

Traditionally, two consecutive azoospermic samples are obtained prior to clearance. A study comparing men with two tests at 12 and 16 weeks versus those with a single test at 16 weeks showed that the proportion of azoospermic men after one semen analysis was the same in both groups. The compliance for the second test at 16 weeks was lower than for the first test in the two-test group, suggesting that a single post-vasectomy semen analysis, if azoospermic, may be adequate. ${ }^{36}$ The RCOG guidelines suggest 'special clearance' for men with persistent non-motile sperm if there are less than 10,000 per $\mathrm{ml}$ in a fresh specimen, at least 7 months' post-vasectomy, ${ }^{5}$ as no pregnancies have been reported at up to 3 years' follow-up. ${ }^{37,38}$

\section{CHRONIC PAIN}

This may result from congestive epididymitis or the development of sperm granuloma. The incidence of chronic orchalgia is quite high $(12-52 \%) .^{5}$ The proportion of patients, however, whose quality of life was affected, or those who sought treatment was much lower $(2.2-15 \%) .{ }^{39-41}$ These studies were questionnaire-based, with a 4-10 year follow-up, and subject to selection bias. Treatment options include excision of sperm granuloma, epididymovasectomy, and vasectomy reversal. ${ }^{5}$ Incidence of chronic pain is reportedly decreased by injecting local anaesthetic agents into the vas at the time of surgery. ${ }^{42}$

\section{IMMUNOLOGICAL}

1. Immune-complex disease - antisperm antibodies develop in over $60 \%$ of men after vasectomy.$^{43}$ However, a large cohort study has shown that these are not associated with immune-complex mediated diseases such as lupus erythematosus, scleroderma and rheumatoid arthritis. $^{44}$
2. Atherosclerosis and heart disease - studies in cynomolgus monkeys found an increased frequency of atherosclerosis in previously vasectomised monkeys who were on a high cholesterol diet. ${ }^{45}$ This was thought to be related to antisperm antibodies, and led to fears that a similar effect might occur in humans. The same authors later reported that the atherosclerosis observed in the monkeys on an atherogenic diet was greater in those hyperresponsive to cholesterol as compared to those hyporesponsive, and that vasectomy had no role in the extent of atherosclerosis. ${ }^{46}$ Several epidemiological studies have also confirmed that there is no increased risk of cardiovascular disease following vasectomy in humans. ${ }^{44,47}$

\section{UROLITHIASIS}

A significant association between urolithiasis and vasectomy has been found. ${ }^{48}$ There are, however, no risk factors for urolithiasis than can be related to vasectomy.

\section{CANCER}

1. Testicular cancer - no increased risk of testicular cancer have been found in large cohort studies involving up to 73,000 men. ${ }^{49,50}$

2. Prostate cancer - Bernal-Delgado et al. ${ }^{51}$ evaluating 5 cohort and 9 case-control studies, found that the overall relative risk for prostate cancer was not significant. A weak association was found between vasectomy and prostate cancer, and this was probably due to medical care-seeking behaviour of the vasectomised men (diagnostic access bias).They concluded that there was no causal relationship between vasectomy and prostate cancer, and that vasectomised men were not at a higher risk of developing prostate cancer. This was later confirmed by Cox et al. ${ }^{52}$ in a retrospective study. The American Urological Association no longer recommends informing patients of a possible risk and considers 'it is very safe to use vasectomy as a form of male sterilisation'.53

\section{DEATH}

Sterilisation-related deaths are often under-reported. Vasectomy is associated with a lower death rate than tubal occlusion. The mortality in industrialised countries is 0.1 per 100,000 vasectomies as compared to 4 per 100,000 tubal occlusions. The corresponding mortality rates in Bangladesh are 19.0 and 16.2 per 100,000 procedures, respectively. ${ }^{54}$ These high rates are mostly attributed to infection and, in case of tubal occlusion, to anaesthetic overdose and haemorrhage as well.

\section{Conclusions}

Vasectomy is a safe and relatively simple method of contraception. It has lower morbidity and mortality than 


\section{Table 1 Common complications at a glance}

\section{Complication}

Haematoma

Infection

Failure after clearance (late recanalisation)

Chronic orchalgia (affecting quality of life)

Autoimmune disease

Atherosclerosis and heart disease

Testicular cancer

Prostate cancer

Death
Incidence

$2 \%$

$3.4 \%$

$0.05 \%$ (1 per 2000)

$2.2-15 \%$

No increased risk

No increased risk

No increased risk

No increased risk

0.1 per 100,000 tubal occlusion. Several large studies have disproved any relationship between vasectomy and the development of immunological, or cardiovascular diseases, or cancer. However, it is not without complications (Table 1). Patients must be counselled about possible side-effects including infection, haematomas, failure of the procedure, chronic pain, and failure of vasectomy reversal in achieving pregnancy. Practitioners must be trained to the level advocated by the Faculty of Family Planning and Reproductive Health Care to minimise the incidence of complications. ${ }^{5}$ This would make vasectomy a more acceptable form of permanent contraception and decrease the incidence of medical negligence claims arising from it.

\section{References}

1. United Nations DoEaSA, Population, Division. Levels and Trends of Contraceptive use as Assessed in 1988. New York: United Nations, 1988.

2. Dawe F, Meltzer H. Contraception and Sexual Health 2001. London: Office for National Statistics, 2003

3. Rowlands S, Hannaford P. The incidence of sterilisation in the UK. Br J Obstet Gynaecol 2003; 110: 819-24.

4. United Nations. World Population Monitoring. New York: United Nations, 2002.

5. Royal College of Obstetricians and Gynaecologists. Male and Female Sterilisation. National Evidence-based Guideline No. 4. London: RCOG Press, 2004

6. Thon WF, Stief CG, Jonas U. [Vasectomy: minor intervention-grave sequelae]. Urologe A 1992; 31: 55-7.

7. Benjamin R. Not all births are 'blessed events': legal perils of vasectomy. Minn Med 1978; 61: 659-61

8. Sokal D, McMullen S, Gates D, Dominik R. A comparative study of the no scalpel and standard incision approaches to vasectomy in 5 countries. The Male Sterilization Investigator Team. J Urol 1999; 162: 1621-5.

9. Chen-Mok M, Bangdiwala SI, Dominik R, Hays M, Irsula B, Sokal DC. Termination of a randomized controlled trial of two vasectomy techniques. Control Clin Trials 2003; 24: 78-84.

10. Li SQ, Hou YH, Li CH, Pan QR, Cheng DS. Relationship between vas occlusion techniques and recanalisation. Adv Contracept Deliv Syst 1994; 10: 153-9.
11. Leissner J, Reiher F, Bohm M, Allhoff EP. [Ambulatory vasectomy. Risks and complications]. Urologe A 2003; 42: 1029-34.

12. Kendrick JS, Gonzales B, Huber DH, Grubb GS, Rubin GL. Complications of vasectomies in the United States. J Fam Pract 1987; 25: 245-8.

13. Goldstein M. Surgical management of male infertility and other scrotal disorders. In: Walsh PC, Retik AB, Vaughan ED, Wein AJ. (eds) Campbell's Urology, 7th ed, vol. 3. Philadelphia, PA: WB Saunders, 1998; 1343.

14. Randall PE, Ganguli L, Marcuson RW. Wound infection following vasectomy. $\mathrm{Br}$ J Urol 1983; 55: 564-7.

15. Appell RA, Evans PR. Vasectomy: etiology of infectious complications. Fertil Steril 1980; 33: 52-3.

16. Sharma J, Sadasukhi TC. Infectious complications of vasectomy: a study of 200 cases. Int Surg 1983; 68: 79-80.

17. Lema VM. Fournier's gangrene complicating vasectomy. East Afr Med J 2003; 80: 492-6.

18. Viddeleer AC, Lycklama A, Nijeholt GA. Lethal Fournier's gangrene following vasectomy. J Urol 1992; 147: 1613-4.

19. Patel A, Ramsay JW, Whitfield HN. Fournier's gangrene of the scrotum following day case vasectomy. J $R$ Soc Med 1991; 84: 49-50.

20. Bai KV. Primary chancres on vasectomy wounds. Br J Clin Pract 1974; 28: 172-3.

21. Dan M, Marien GJ, Goldsand G. Endocarditis caused by Staphylococcus warneri on a normal aortic valve following vasectomy. Can Med Assoc J 1984; 131: 211-3.

22. Lessing MP, Crook DW, Bowler IC, Gribbin B. Native-valve endocarditis caused by Staphylococcus lugdunensis. Q J Med 1996; 89: 855-8.

23. Kessler RB, Kimbrough 3rd RC, Jones SR. Infective endocarditis caused by Staphylococcus hominis after vasectomy. Clin Infect Dis 1998; 27: 216-7.

24. Fervenza FC, Contreras GE, Garratt KN, Steckelberg JM. Staphylococcus lugdunensis endocarditis: a complication of vasectomy? Mayo Clin Proc 1999; 74: 1227-30.

25. Seidi J, Brotzman G. The rate of hydrocele perforation during vasectomy. Is perforation dangerous? J Fam Pract 2000; 49: 537-40.

26. Murovic JA, Kim DH, Tiel RL, Kline DG. Surgical management of 10 genitofemoral neuralgias at the Louisiana State University Health Sciences Center. Neurosurgery 2005; 56: 298-303, discussion 298-303.

27. Desai KM, Abrams P. Vasal urinary fistula with retrograde reflux of urine after vasectomy. J Urol 1986; 135: 1023-4. 
28. Assimos DG, Basile JJ, Boyce WH. Urethrovasocutaneous fistula. Urology 1988; 31: 338-9.

29. Balogh K, Argenyi ZB. Vasitis nodosa and spermatic granuloma of the skin: an histologic study of a rare complication of vasectomy. J Cutan Pathol 1985; 12: 528-33.

30. Rajan RR, Cuesta KH, Squadrito Jr J. Vasovenous fistula after vasectomy. J Urol 1997; 158: 2243.

31. Auman JR. Spermatic cord arteriovenous fistula: an unusual complication of vasectomy. J Urol 1985; 134: 768.

32. Silber SJ. Sperm granuloma and reversibility of vasectomy. Lancet 1977; 2 : 588-9.

33. Schmidt S. Technics and complications of elective vasectomy. The role of spermatic granuloma in spontaneous recanalisation. Fertil Steril 1966; 17: 467-82.

34. Philp T, Guillebaud J, Budd D. Late failure of vasectomy after two documented analyses showing azoospermic semen. BMJ (Clin Res Ed) 1984; 289: 77-9.

35. Labrecque M, Nazerali H, Mondor M, Fortin V, Nasution M. Effectiveness and complications associated with 2 vasectomy occlusion techniques. J Urol 2002; 168: 2495-8; discussion 2498.

36. Badrakumar C, Gogoi NK, Sundaram SK. Semen analysis after vasectomy: when and how many? BJU Int 2000; 86: 479-81.

37. Philp T, Guillebaud J, Budd D. Complications of vasectomy: review of 16,000 patients. Br J Urol 1984; 56: 745-8.

38. Davies AH, Sharp RJ, Cranston D, Mitchell RG. The long-term outcome following 'special clearance' after vasectomy. Br J Urol 1990; 66: 211-2.

39. McMahon AJ, Buckley J, Taylor A, Lloyd SN, Deane RF, Kirk D. Chronic testicular pain following vasectomy. Br J Urol 1992; 69: 188-91.

40. Choe JM, Kirkemo AK. Questionnaire-based outcomes study of nononcological post-vasectomy complications. J Urol 1996; 155: 1284-6.

41. Manikandan R, Srirangam SJ, Pearson E, Collins GN. Early and late morbidity after vasectomy: a comparison of chronic scrotal pain at 1 and 10 years. BJU Int 2004; 93: 571-4.
42. Paxton LD, Huss BK, Loughlin V, Mirakhur RK. Intra-vas deferens bupivacaine for prevention of acute pain and chronic discomfort after vasectomy. $\mathrm{Br} J$ Anaesth 1995; 74: 612-3.

43. Fuchs EF, Alexander NJ. Immunologic considerations before and after vasovasostomy. Fertil Steril 1983; 40: 497-9.

44. Massey Jr FJ, Bernstein GS, O'Fallon WM, Schuman LM, Coulson AH, Crozier R et al. Vasectomy and health. Results from a large cohort study. JAMA 1984; 252: 1023-9.

45. Alexander NJ, Clarkson TB. Vasectomy increases the severity of diet-induced atherosclerosis in Macaca fascicularis. Science 1978; 201: 538-41.

46. Clarkson TB, Alexander NJ, Morgan TM. Atherosclerosis of cynomolgus monkeys hyper- and hyporesponsive to dietary cholesterol. Lack of effect of vasectomy. Arteriosclerosis 1988; 8: 488-98.

47. Coady SA, Sharrett AR, Zheng ZJ, Evans GW, Heiss G. Vasectomy, inflammation, atherosclerosis and long-term follow-up for cardiovascular diseases: no associations in the atherosclerosis risk in communities study. J Urol 2002; 167 : 204-7.

48. Kronmal RA, Alderman E, Krieger JN, Killip T, Kennedy JW, Athearn MW. Vasectomy and urolithiasis. Lancet 1988; 1: 22-3.

49. Moller $\mathrm{H}$, Knudsen LB, Lynge E. Risk of testicular cancer after vasectomy: cohort study of over 73,000 men. BMJ 1994; 309: 295-9.

50. Strader $\mathrm{CH}$, Weiss NS, Daling JR. Vasectomy and the incidence of testicular cancer. Am J Epidemiol 1988; 128: 56-63.

51. Bernal-Delgado E, Latour-Perez J, Pradas-Arnal F, Gomez-Lopez LI. The association between vasectomy and prostate cancer: a systematic review of the literature. Fertil Steril 1998; 70: 191-200.

52. Cox B, Sneyd MJ, Paul C, Delahunt B, Skegg DC. Vasectomy and risk of prostate cancer. JAMA 2002; 287: 3110-5.

53. American Urological Association. Vasectomy and prostate cancer $<$ http://www.auanet.org/about/policy/services.cfm\#vasectomy>.

54. Rubin GL, Ory HW, Layde PM. The mortality risk of voluntary surgical contraception. Biomed Bull 1982; 3: 1-5. 